\title{
O SISTEMA GLIM
}

Gauss M. Cordeiro*

O GLIM (sigla de "Generalized Linear Interactive Modelling") é um programa estatístico-computacional iterativo desenvolvido pela Royal Statistical Society, sendo distribuído pela NAG (Numerical Algorithms Group), Wilkinson House, Jordan Hill Road, Oxford, OX2 8DR, UK. Ele se mostra indispensável para o tratamento de dados complexos que surgem em muitos problemas econométricos e nas àreas de Ciências Sociais, Engenharia, Física, Biologia e Química.

O GLIM visa, principalmente, a ajustar a classe de modelos lineares generalizados. Esta classe de modelos, desenvolvida em 1972, engloba várias técnicas estatísticas e modelos usuais para a análise de dados univariados. E o que é mais importante, generaliza os modelos econométricos clássicos em duas direções. Primeiro, a variável resposta pode ser diferente da normal, pertencendo a uma família ampla de distribuições de probabilidade. Segundo, a média da variável resposta pode ser dada por uma função não-linear da estrutura sistemática usual dos modelos econométricos. Assim, as hipóteses básicas de normalidade, linearidade e homocedasticidade não são exigidas para a análise de dados via o GLIM.

Em adição ao ajustamento de modelos estatísticos e econométricos', o GLIM é usado para manipulação de dados, cálculos estatísticos, tranformação de variáveis, geração de variáveis aleatórias, análise de resíduos e representação gráfica de dados. O GLIM é uma linguagem estatístico-computacional de ajustamento de modelos econométricos (lineares e não lineares, normais e não-normais), constando de uma série de 70 diretivas, 20 vetores, 25 funções e 15 escalares pré-definidos.

Um programa em linguagem GLIM pode ter de 5 a 5000 linhas em uma ordem lógica que englobe: definição dos dados, manipulação de dados, especificação e ajustamento de modelos, obtenção dos resultados dos ajustamentos, controle de entrada, saída e de execução e inspeção sobre o seu sistema operacional. Isto o destaca da maioria dos pacotes estatísticos e econométricos.

*Departamento de Economia da UFPE e IMPA/CNPq

\begin{tabular}{llll}
\hline R. de Econometria & Rio de Janeiro & v. XI, $n^{0}$ 1, p.141-142 & abril 1991
\end{tabular}


A última versão do GLIM, denominada 3.77 , tem um bom manual de utilização (adquirido com o pacote) que contém um resumo da teoria dos modelos lineares generalizados, um guia completo descritivo das dirctivas do programa, excmplos de utilização c bibliografia relevante. O usuário pode ainda contar com uma biblioteca de macros acoplada ao programa com diversas finalidades. Estc pacote já foi distribuído para mais de 60 países c está disponível para quase todas as configuraçōes de microcomputadores c "mainframes".

É surprecndente como o GLIM, apesar de ser utilizado cm todas as universidades inglesas c na maioria das americanas, ainda não conseguiu popularidade sufuciente no Brasil. 